\title{
Entre práticas e invenções cotidianas: fragmentos narrativos sobre degradação ambiental e Saúde em Aracaju, Brasil
}

\author{
Between everyday practices and interventions: narrative \\ fragments on environmental degradation and health \\ in Aracaju, Brazil
}

\author{
Lázaro Batista da Fonseca ${ }^{1}$ \\ Maria Teresa Nobre ${ }^{2}$ \\ João José Gomes dos Santos ${ }^{3}$
}

${ }^{1}$ Departamento de Psicologia, Universidade Federal de Roraima. Av. Capitão Ene Garcez 2413, Aeroporto. 69.310-000 Boa Vista RR Brasil.lazzarobf@ hotmail.com

${ }^{2}$ Departamento de Psicologia, Universidade Federal do Rio Grande do Norte.

${ }^{3}$ Universidade Federal do

Espírito Santo.

\begin{abstract}
The scope of this paper is to describe the relationship between health production, urban growth and environmental degradation in the community of the "Urban Expansion Zone" of Aracaju in the State of Sergipe. It also touches on the impacts on the health of the population due to tourism and real estate speculation associated with the absence of basic services. Based on the assumption that illnesses caused by such changes only appear on the public health care system as a worsening of symptoms, neglecting the complex. health-environment relationship, this paper highlights the possibility of pondering the bases upon which urban growth occurs in the light of imminent environmental degradation. The activities of health community agents were monitored duly connecting them to regional growth and environmental degradation. This was done from March 2010 and June 2011 adopting the ethnographic perspective as the method of choice. Other ways of inclusion in the community were mapped: contact with older residents, religious leaderships and the members of the traditional professions, etc. The results show the changes that have been occurring in the region, especially with respect to the extinction of traditional practices, increase in violence, unemployment, loss of community ties and illness. Key words Health, Environmental degradation, Urban growth
\end{abstract}

Resumo Descreve as relações entre produção de saúde, crescimento urbano e degradação ambiental no povoado da "Zona de Expansão Urbana" de Aracaju (SE) e os impactos na saúde da população, em virtude do turismo e da especulação imobiliária, aliados à ausência de serviços básicos. Partindo da hipótese de que o adoecimento gerado por essas mudanças apareceriam na rede de saúde pública apenas como agravamento de sintomas, negligenciando-se a complexidade da relação saúde-ambiente, o trabalho aponta a possibilidade de pensarmos em que bases se dá o crescimento urbano, às expensas da degradação ambiental. Adotando a etnografia como método, entre março de 2010 e junho de 2011, acompanhamos as ações de agentes comunitários de saúde, a maneira como estes e os demais profissionais da Estratégia Saúde da Família (ESF) lidam com os problemas trazidos pelos moradores, relacionando-os ao crescimento da região e à degradação ambiental. Outros meios de inserção na comunidade foram mapeados: contato com moradores mais antigos, lideranças religiosas, pessoas que exercem profissões tradicionais, etc. Os resultados traduzem as mudanças pelas quais passa a região, especialmente naquilo que se refere à extinção de práticas tradicionais, aumento da violência, desemprego, perda de vínculos comunitários e adoecimentos.

Palavras-chave Saúde, Degradação ambiental, Crescimento urbano 


\section{Notas introdutórias}

Num dia escuro de trovoada, como outros tantos de um janeiro qualquer, um rádio ligado anuncia mais um empreendimento imobiliário naquela que diz ser a região mais próspera para se morar em Aracaju, capital de Sergipe: Na Zona de Expansão, vizinha ao aeroporto, diz o anúncio.

As chuvas de trovoada, que nos apresentam a propaganda do rádio, certamente são as mesmas que em 2010 assolaram essa tal "Zona de Expansão”. Chegamos por lá um pouco depois delas, mas pudemos perceber sua presença nas marcas deixadas na região. Essas mesmas chuvas, que nos levaram ao anúncio do novo prédio, anunciaram, em meados do ano anterior, aos moradores da área, alguns graves problemas com os quais eles tiveram e têm ainda que conviver, ao tempo em que vozes do Estado os acusaram como os corresponsáveis por tais mazelas - pois constroem suas casas em áreas por onde as águas da chuva não conseguem escoar; pois não costumam dar um destino correto ao lixo; pois usam água poluída pelo lixo e pelas fossas.

Nos estrondos de seus trovões, essas vozes falavam em degradação ambiental, em ocupação desordenada, riscos à saúde e especulação imobiliária. Palavras já ouvidas por aquelas bandas, mas cujos significados começavam a tomar corpo somente naquele momento, na medida em que os efeitos produzidos por tais palavras tornavam-se cada vez mais sentidos na vida cotidiana dos habitantes.

É sobre estes efeitos que o presente texto busca deter-se, problematizando algumas questões. Seu objetivo principal é apontar relações entre a degradação ambiental da chamada "Zona de Expansão Urbana” de Aracaju e os impactos que ela produz na saúde da população local, em virtude do modelo de urbanização adotado como política governamental, do incremento do turismo e da especulação imobiliária, aliados à ausência de serviços básicos como: saneamento, coleta de lixo, tratamento da água e esgoto, etc.

Os poucos equipamentos de serviços públicos, tais como acesso ao transporte, segurança, praças e áreas de lazer, contrastam com a construção das maiores mansões da cidade, com acesso privativo ao rio e prática de esportes aquáticos de elite, dificultando a pesca e a comercialização do pescado, evidenciando assim a “expansão" do enorme acirramento das desigualdades sociais da cidade. Tanto para atender ao incremento do turismo e às demandas de setores mais privilegiados, quanto às necessidades de expansão urbana com moradias populares, a ocupação do terreno, tanto nas áreas litorâneas, quanto nas mais afastadas, se dá através do desmonte de dunas, aterramento de mangues e lagoas, assim como pela devastação dos coqueirais ${ }^{1}$. Somados às condições precárias ou ausentes de drenagem e escoamento sanitário, o que se verifica é a alarmante degradação ambiental na região, destacando-se problemas caóticos de alagamento durante o período de chuvas.

Além dos problemas referentes à ocupação do território, os impactos sobre a saúde se fazem sentir nas mudanças dos modos de vida, de trabalho, de moradia, de uso do tempo, da relação entre as pessoas. Alia-se aos novos modos de adoecimento produzidos pela/na relação com o ambiente, a perda das tradições de cuidado com o corpo e com a saúde, tais como práticas de cura religiosa, mística ou mágica, que podem ser entendidas como modos de produção de saúde, associados ou não, aos usos que as pessoas fazem da rede de saúde pública. Nessa perspectiva, consideramos que o território não diz respeito apenas aos limites geográficos formados pelos sistemas naturais, mas também e, sobretudo, os acréscimos que os homens superpuseram a eles, reunindo a materialidade do espaço e a vida que o anima ${ }^{2}$.

Partimos do pressuposto que os adoecimentos gerados por essas mudanças aparecem na rede de saúde pública apenas como agravamento de sintomas de doenças sem evidenciar a complexidade da relação saúde-ambiente, a menos que as consequências da degradação ambiental, do mau uso dos recursos ambientais, das práticas de descuido ou negligência produzam epidemias graves - como a dengue, por exemplo.

Com base nesse cenário, a pesquisa da qual resulta este artigo pretendeu, através das narrativas dos moradores, conhecer os processos de expansão urbana da cidade de Aracaju em um de seus mais tradicionais povoados, atentando para os impactos sobre a saúde da população local, bem como para os modos de reinventar a vida e as relações afetivas ou sociocomunitárias, desenvolvidas em meio às mudanças na região.

Adotando a perspectiva etnográfica como delineamento metodológico, a pesquisa propôs analisar as relações descritas acima a partir de duas frentes: acompanhando o trabalho de visitas domiciliares realizado pelas Agentes Comunitárias de Saúde (ACS); bem como realizando caminhadas pelo povoado, tecendo conversas com moradores mais antigos e/ou líderes comunitários. Usando o recurso da observação (livre, 
sistemática ou participante) buscamos conhecer os modos de vida dos moradores, que na sua singularidade fazem enfrentamento aos problemas causados pela degradação ambiental, sobretudo no que diz respeito às práticas de produção de saúde e cura.

A partir daí, tentamos construir um mosaico da configuração sócio-espacial do entorno, atentando para as maneiras como as ACS, junto à comunidade, lidam com os problemas mais recorrentes, e se estes se relacionam de alguma forma com os traços de crescimento acelerado da cidade e da região, especialmente no campo da saúde.

\section{Delimitações do campo teórico}

Por se tratar de um estudo interessado em deter-se sobre questões relacionadas a temas como adoecimento, saúde, meio ambiente e narrativa, torna-se premente, antes de qualquer coisa, definirmos o entendimento que estamos dando a esses termos.

Comecemos, assim, por uma concepção de saúde como algo para muito além da mera ausência de doenças, mas como potência de (re) invenção da vida. Ou como define a Organização Mundial da Saúde (OMS), um "estado de completo bem-estar físico, mental e social, e não somente a ausência de enfermidade ou invalidez", levando em conta "a satisfação plena das necessidades das pessoas, grupos e populações”. Concepção ratificada quarenta anos depois, na Conferência Internacional sobre Promoção de Saúde, realizada em Ottawa, em 1986, ao postular a ideia da saúde como qualidade de vida resultante de complexo processo condicionado por diversos fatores, tais como: alimentação, justiça social, ecossistema, renda e educação ${ }^{3}$. Neste evento são propostas estratégias de ação para cuidados ambientais e promoção da saúde, evidenciando a estreita relação entre os dois campos ${ }^{4}$.

Signatário dessas convenções, o Brasil, sob pressão do Movimento da Reforma Sanitária, incorpora no texto Constitucional de 1988, no seu Art. 196, a ideia de saúde como direito de todos e dever do Estado, garantido mediante políticas sociais e econômicas que visem à redução do risco de doença e o acesso universal e igualitário aos serviços de promoção, proteção e recuperação da saúde ${ }^{5}$.

Tal proposição é consolidada pela Lei 8.080/906 , a chamada Lei Orgânica da Saúde, que regulamentou a criação do SUS (Sistema Único de Saúde), reconhecendo como fatores determi- nantes e condicionantes do processo saúde-doença, entre outros: a alimentação, a moradia, o saneamento básico, o meio ambiente, o trabalho, a renda, a educação, o transporte, o lazer e o acesso aos bens e serviços essenciais. Essa formulação engloba as condições e o contexto em que as pessoas estão inseridas, ultrapassando o velho binômio saúde-doença e deslocando o foco das ações centradas no indivíduo para as ações focadas no território onde ele vive. Com isso a prevenção e a promoção da saúde ganham ênfase e relevância nos programas e serviços de saúde, embora na prática essa dicotomia não tenha sido superada, prevalecendo um atendimento ainda centralizado na perspectiva biomédica, no qual as relações de poder-saber entre as gestões das políticas públicas e serviços, corporações profissionais e usuários do sistema permaneçam intocadas em larga escala - o que repercute sobre o modo de funcionamento institucional das organizações de saúde.

Por outro lado, a necessidade de politizar a discussão sobre a garantia do direito à saúde $\mathrm{e}$ sua relação com os determinantes sociais do processo saúde-doença pautou as diretrizes do novo modelo em princípios clássicos do sanitarismo tradicional, enfatizando o papel do Estado. Posteriormente aponta-se a necessidade de ampliação dessa concepção, incluindo ações mais abrangentes e a responsabilização de novos atores sociais. O surgimento do conceito de desenvolvimento sustentável e a proposta da Agenda 21 na Conferência Rio-92, que representam a assunção do compromisso dos quase duzentos países signatários com um novo padrão de desenvolvimento em substituição aos processos predatórios predominantes no século XX, são um marco nesse processo de mudança ${ }^{4}$.

Além disso, a concepção de saúde como "estado de completo bem-estar" aponta uma situação inatingível, já que, como afirma Canguilhem ${ }^{7}$, a saúde perfeita só existe como categoria de tipo ideal. Para ele, saúde e doença, normal e patológico são dimensões qualitativamente distintas definidas por um critério de plasticidade e produção de sentido: a possibilidade de transitar entre várias normas traduz o estado de normalidade. Já a fixação em uma norma, hermética e rígida, a patologia. Assim, a experiência do adoecimento e da produção de saúde é permeada por construções de normas coletivas, sociais e históricas, situadas num tempo, numa cultura, num espaço, num lugar, num sistema de valores. Ter saúde implica, portanto, possibilidades de produção de novos modos de vida, flexibilidade de ir e vir entre diferentes normas, de aderir a elas, 
mas também de contrariá-las: modos singulares e partilhados de existência e de convivência com a doença, com o mundo, com a natureza.

Assim, segundo essa perspectiva ampliada de saúde, podemos pensar que as discussões sobre meio ambiente situam-se além do detalhamento dos impactos causados pela ação humana sobre os ecossistemas naturais, para serem encarados como componentes cruciais para a produção de vida das pessoas que habitam áreas ou contextos de degradação ambiental ${ }^{8}$. Pois as doenças e a saúde estão diretamente vinculadas às condições de vida, aos estilos de viver, de se relacionar com os outros e com o ambiente. Tem-se, dessa maneira, uma perspectiva de saúde como um bem concreto que deve ser visto a partir de determinantes e condicionantes históricos, genéticos e estruturais (biopsíquicos, sociais e ecológicos) e na inter-relação entre eles?.

Isso faz ressoar, inclusive, a discussão sobre ecologia para fora dos círculos fechados, historicamente engajados na problemática. Temos aí a colocação da ecologia como um problema político $^{10}$, na medida em que move a sociedade para repensar as bases sobre as quais se dá seu desenvolvimento e sustentação. Ou seja, não se restringem a apontar as consequências da degradação sobre os meios naturais, mas colocam em pauta o quanto essa devastação também afeta os modos de vida humanos, seja produzindo a mortificação das relações afetivas, seja inviabilizando modos de vida tradicionais. Além disso, ressaltam eles, partindo desse entendimento, a questão ecológica assume importância para os envolvidos, já que se trata agora de preservar sua sobrevivência.

De modo muito semelhante, para Guattari ${ }^{11}$, o que está posto nesse outro modo de entendermos a ecologia é o reconhecimento de um paradigma ético-estético-político, ao qual denomina "ecosofia". Para ele, a continuidade da vida somente pode ser assegurada a partir da afirmação e articulação entre meio ambiente, subjetividade e relações sociais. Em linhas gerais, não se trataria apenas de discutir em que pé encontra-se a devastação ambiental, mas de circunscrevê-la no atual estado de coisas do mundo, de pôr em xeque nossos sistemas de valores, de fazer emergir outros em seu lugar; de reinventar os modos de relação do homem consigo, com o outro e com o mundo; de pormo-nos abertos aos encontros com o novo e o inesperado e, finalmente, de (re) pensarmos os destinos da humanidade.

Retornemos agora à ideia de saúde, constitucionalmente assegurada e transformada nos princípios doutrinários do SUS: o acesso univer- sal, integral e equânime de todos aos cuidados à saúde. Certamente o novo modelo representou um avanço em relação a antigas práticas de saúde pública, mas, fato é que, mesmo institucionalizados, estes princípios não foram plenamente implementados e o que se vê nesses vinte e poucos anos depois é um sistema que comporta, ao mesmo tempo, conquistas e entraves gigantescos, produzindo o que Campos ${ }^{12}$ nomeia como uma "síntese sanitária paradoxal": ganhos epidemiológicos importantes de um lado e, de outro, a degradação das condições de vida e saúde da população. Estão incluídas aí as contradições do próprio sistema no que diz respeito à sua capacidade resolutiva, qualidade de atendimento, modelos de gestão, financiamento e uso dos recursos.

A despeito disso, há também modos de enfrentamento dos profissionais da saúde que tramam alternativas para sustentação da ideia de saúde como o atendimento integral e que se inventam a cada nova necessidade que surge no dia-a-dia dos serviços. Um exemplo disso são algumas ações das equipes da Estratégia Saúde da Família (ESF), particularmente dos agentes comunitários de saúde (ACS). Em grande parte devido às práticas de atenção e cuidado que muitas das vezes não coincidem com as indicações das políticas públicas, mas com os modos locais, cotidianos e ordinários, de se viver e fazer viver.

É exatamente no diálogo que realiza com essas práticas ordinárias, reafirmando os laços de proximidade com a comunidade, para além dos modos de intervenção programáticos, que essa iniciativa pode se tornar frutífera. E, como aponta Lancetti ${ }^{13}$, eis aí o principal componente de certa "potência terapêutica" do trabalho dos ACS: o de singularizarem-se por essa condição paradoxal de serem "ao mesmo tempo membros da comunidade e integrantes da organização sanitária". Uma imbricada relação de invenção e fortalecimento das redes de sociabilidade entre o agente comunitário e as pessoas, orientada para a busca de soluções aos problemas locais. Isso, porém, sem desconsiderar os personagens envolvidos, nem os relegando a uma condição subalterna em relação às políticas oficiais que esses mesmos agentes representam.

Caminhando entre estas ferramentas entendemos ser possível uma escrita da vida cotidiana no meio urbano, tendo como foco essas práticas de cuidado à saúde, que incluem seus modos de viver, de trabalhar, de circular, de narrar, de habitar espaços, situadas num tempo e num lugar. Para De Certeau ${ }^{14}$,"o cotidiano se inventa com mil maneiras de caça não autorizada”. Isso indica 
que, em suas práticas, o homem comum, usuário supostamente submetido à passividade e à disciplina, exerce uma "uma política do agir cotidiano”. Suas ações seriam “operações quase microbianas que proliferam no seio das estruturas tecnocráticas e alteram o seu funcionamento por uma multiplicidade de 'táticas' articuladas sobre os 'detalhes' do cotidiano".

Neste sentido, a atividade narrativa, entendida como um fazer político, assumiu um lugar de destaque no trabalho de campo. Diante da tentativa de abafar modos de vida que destoam da programação disciplinar moderna, narrar o cotidiano surge como um paradoxo a esse cerceamento. Surge como fala de um, que se junta a mais um, depois outro. Flagrante delito de fabular de um, que com mais um com-fábula ${ }^{15}$. E assim produz-se micropolíticas ${ }^{16}$. Melhor ainda, inventa-se uma política de encontros ${ }^{17}$.

Vale ressaltar que nesse seu componente político, narrar aparece como algo da ordem das descontinuidades, do fragmentado e inconcluso. Quando narramos, o fazemos por retalhos, enredamentos e fiamentos. A despeito de uma construção que obedeça à lógica, uma narrativa segue um percurso indefinido e indeterminado. Faz-se à medida que vai se fazendo. E, além, obviamente, de solver a pretensão de se chegar à segurança das construções resolutas, isso quebra o binarismo entre quem diz e quem conta. Avessa à cisão entre objeto e sujeito, que um conhecimento pretensamente neutro promulga, a narrativa se tece, portanto, por intercessores e, como tal, é mistura de ditos ${ }^{18}$.

Enfim, se narrar e ouvir são elementos preciosos das práticas de cuidado - ou mesmo condição indispensável nas ações de saúde protagonizadas pelos profissionais da ESF e, em particular, dos ACS, por outro lado, a experiência da narração não pode ser ensinada ou aprendida por vias formais. Ao contrário, portanto, do que propõem os programas de educação em saúde, ao suporem essa capacidade de "escuta qualificada" dos profissionais, que também devem transmitir informações e serem capacitados para o desempenho dessas funções. Para além dessas exigências, postas ao ofício de cuidar das pessoas, a atividade narrativa pressupõe o encontro entre elas, algo da ordem dos vínculos afetivos, do prestígio ou da tradição, que lhes permita a condição fundamental, perdida e esquecida da narração: a capacidade de trocar experiências ${ }^{19}$.

\section{Saúde, degradação ambiental e modos de fazer da pesquisa}

Tomamos como porta de entrada, para a investigação da problemática da pesquisa, as práticas da Unidade Básica de Saúde (UBS) de um dos povoados que compõem a Zona de Expansão Urbana e sua assistência às populações locais por meio do trabalho da equipe da ESF. Em especial, privilegiando o acompanhamento das ACS em visitas às famílias da região e de nossas caminhadas errantes pelo povoado.

A inserção no campo da pesquisa foi inicialmente possível através do acesso à Gerência da UBS, que nos colocou em contato com a equipe da ESF, formada por um médico clínico geral, um dentista, uma enfermeira, um auxiliar de enfermagem, uma assistente social e oito ACS, responsáveis pelo atendimento dos aproximadamente seis mil habitantes do povoado. Com as últimas realizamos uma reunião para conversar sobre a pesquisa e o que pensávamos como metodologia de trabalho, reafirmando as visitas domiciliares como principal instrumento. Essa negociação, que antecedeu a nossa entrada no campo, inverteu o caminho que normalmente se traça do ponto burocrático: como forma de legitimar nossa inserção, entendíamos que essa autorização precisaria ser dada primeiramente pelas pessoas que participariam da pesquisa, antes mesmo de ser aprovada pela equipe de Educação Permanente da Secretaria Municipal de Saúde.

Feita essa pactuação, a metodologia de acercamento do nosso objeto teve como lócus privilegiado a UBS para a qual nos dirigíamos semanalmente e de onde o nosso trabalho de construção dos dados partia. Em geral, chegávamos muito cedo, participávamos do acolhimento coletivo realizado pelo médico e pela enfermeira e, em seguida, saiamos com as ACS para as visitas domiciliares, numa média de cinco por turno. Outras vezes permanecíamos na própria UBS, conversando com os usuários enquanto esperavam consultas, vacinação ou outros procedimentos ou, ainda, com os demais profissionais da equipe da ESF. Não adotamos um roteiro fechado para essas conversas informais, salvo as entrevistas semiestruturadas com o médico e com a enfermeira.

O "mote" que orientava as conversas, tanto no espaço da UBS, quanto nas visitas domiciliares e em nossas andanças no povoado, eram as mudanças ocorridas com o incremento do turismo e especulação imobiliária na área, os problemas causados pelas inundações e as demandas que levavam as pessoas a procurarem atendimento 
na UBS. As visitas domiciliares nos permitiam o acesso aos lugares mais recônditos do povoado, nos quais se evidenciavam claramente os problemas ambientais e seus impactos sobre a saúde, aspectos que serão descritos a seguir.

Em todas as fases do trabalho de campo, demos especial atenção aos registros feitos em diário de campo. Nele, foram registradas as conversas, as observações das situações vivenciadas e as impressões do pesquisador, como parte imprescindível das análises das nossas implicaçõe ${ }^{20}$. Assim, a escrita do diário de campo é parte indispensável do trabalho que, em outras perspectivas metodológicas, seriam identificadas como "coleta de dados". Preferimos considerar que dados não são "coletados", pois que não estão disponíveis como "reveladores" de uma "realidade" que constitui o campo. Dados são colhidos, construídos, tecidos, costurados, o que exige um esforço do pesquisador para além da sua apreensão. Enfim, não são informações a serem passivamente ouvidas e inventariadas, são experiências a serem compartilhadas. Por isso, a discussão sobre a escrita do diário de campo, o que nele é registrado a cada visita e que vai alimentar a pesquisa, nas suas novas inserções no campo e na análise dos seus resultados, tem sido, na nossa experiência, parte obrigatória dos encontros coletivos de orientação: uma visita ao campo é sempre registrada, lida, contada e compartilhada, o que produz novas escritas, lidas e entendimentos coletivos da equipe de pesquisadores, sobre o que se vê, se vive e se diz no/do campo.

\section{Sobre o método}

Optou-se por uma perspectiva etnográfica de pesquisa, por entendermos que ela contribui para a produção de um conhecimento que se faz 'no caminhar', com as relações, as práticas, os afetos, os desejos, as crenças. Ou os "imponderáveis da vida real", detalhes da vida cotidiana, as rotinas, o comum, o corriqueiro, os cuidados, os laços de simpatia ou aversões, enfim, os modos de viver, mas também o que é raro, pouco usual e incomum. Essa seria a principal característica do método etnográfico: apreensão de dados sobre o campo pelos quais a carne e o sangue da vida preenchem o esqueleto vazio das construções $\operatorname{abstratas}^{21}$.

Já aqui se ressalta o rigor metodológico inerente à etnografia. Como ela se interessa de forma semelhante tanto por aquilo que salta aos olhos do pesquisador, quanto pelas minúcias de gestos e comportamentos, a atenção do etnógrafo deve voltar-se para a busca de estratégias ou táticas de acercamento do seu objeto, tantas quantas forem possíveis. Temos, assim, uma "saturação nos resultados", um modo de cercar o objeto por todos os lados, de maneira que depois de certo tempo suas características pareçam emergir "naturalmente" 22 .

Percebe-se, assim, que o deixar o campo de pesquisa nos guiar e o 'gastar' tempo nele e com ele (típicos da etnografia) exigem do pesquisador um rigor diferente que é a dimensão da sua implicação, em nos posicionar politicamente, em sermos testados pelo campo, em agir. Como aponta Laplantine ${ }^{23}$, esta é verdadeiramente uma "revolução do olhar", "um olhar que se demora no que vê e se deixa abordar pelo inesperado e pelo imprevisto", capaz de tornar familiar o que é estranho, ao mesmo tempo em que desvela em estranheza aquilo que os olhos nos acostumaram a considerar como familiar.

Assim sendo, ele propõe a distinção entre o ver e olhar, apontando para o "caráter decididamente carnal" do último. Ele seria algo mais do que o ver apenas, por atentar para as diferenças singulares de cada contexto cultural e histórico e, por isso mesmo, nos afastar dos determinismos, generalizações e naturalizações.

Enfim, essa capacidade de mostrar a multidimensionalidade dos fenômenos singulares e concretos que investiga potencializa a etnografia como um método rico para pesquisa no campo da saúde coletiva, sobretudo, por impor aos pesquisadores o desafio de uma interrogação permanente sobre as relações entre o que se vê no campo e o que se diz dele, ou sobre ele, estabelecendo-se, assim, um diálogo permanente entre a observação e a descrição. Seja com base em registros de diários de campo, nas narrativas das pessoas, nas observações livres ou dirigidas da dinâmica da vida cotidiana e dos modos de funcionamento institucional.

\section{Primeiro momento: o trabalho com as Agentes Comunitárias de Saúde}

Dentro dessa abordagem metodológica, nos pusemos a acompanhar o trabalho das ACS no povoado, tentando nas andanças com elas apreender um pouco da dinâmica local, das relações entre agentes e as pessoas, dos modos locais de lidar com o crescimento da região e as possíveis consequências dele, sobretudo daqueles que têm impacto sobre a saúde da população, além de mapear outros possíveis meios de nos inserirmos na comunidade. 
Essa consistiu a primeira etapa do trabalho de campo, a qual se seguiram visitas a moradores mais antigos, rezadeiras e observações livres. No caso das visitas com as ACS, estas eram semanais e se deram entre os meses de março a dezembro de 2010. A elas se somaram participação nas reuniões da equipe da ESF e com grupos de usuários, além de festas e confraternizações da comunidade, para as quais fomos convidados, sinalizando o reconhecimento das ACS e de outros profissionais à nossa inserção no campo.

De modo geral, a atividade de pesquisa nesse momento consistiu em observar se de algum modo o crescimento urbano e a degradação ambiental apareciam como causas de adoecimento entre os moradores, como as ACS lidavam com esses problemas e de que modo as queixas de adoecimento chegavam até a UBS: se diretamente relacionadas com o crescimento da área, ou se "camufladas" nos casos de agravamento de sintomas de outras doenças (tuberculose, pneumonia, doenças de pele, problemas respiratórios, etc.), provocadas pelo contato com a fumaça das queimadas, o uso impróprio da água em tempos de chuvas e alagamentos, ou pela exposição a fatores de risco ambiental.

\section{Segundo momento: deambulações pelo campo}

Após esse levantamento das demandas mais freqüentes na UBS e reconhecimento das dinâmicas da comunidade, a pesquisa voltou-se para um contato mais próximo com moradores, sem que fosse necessária a intermediação das ACS. Essa segunda etapa da pesquisa compreendeu os meses de março até junho de 2011. Durante esse período foram feitas inúmeras visitas à comunidade, com o intuito de conversar sobre a história da localidade e sobre outras formas de produção de saúde, vinculadas a conhecimentos tradicionais de cura e cuidados com o corpo e com o ambiente.

Nesta etapa, retornamos a algumas casas antes visitadas, retomamos contatos com pessoas que durante as visitas domiciliares, acompanhando as ACS, nos pareceram informantes importantes, mas com os quais, em virtude do procedimento adotado de apenas acompanhar o trabalho das ACS, tentando interferir o mínimo em sua rotina, não pudemos firmar um contato mais próximo senão agora. Outros foram contatados por serem moradores antigos e terem vivenciado de perto os processos de mudanças locais, ou por ocuparem lugares estratégicos na vida da comunidade, tais como rezadeiras e pais-de-santo. Esse segundo momento da pesquisa marca uma relação mais próxima com os moradores, conversando mais informal e demoradamente com eles.

Além disso, esta segunda etapa também ajudou-nos a alargar a visão sobre o campo, principalmente em dois aspectos. Em primeiro lugar, porque serviu para dimensionar o quão importante havia sido o fato de termos adentrado à vida do povoado, intermediados pelas ACS, o que nos deu reconhecimento e pareceu nos credenciar também à escuta da comunidade, sem entremeios ou receios. Em segundo, porque ele demarcou um corte temporal de três meses na pesquisa, importante para que exercêssemos o estranhamento que o procedimento etnográfico sugere.

\section{O que dizem as narrativas do cotidiano?}

Durante o trabalho de campo foram visitadas mais de cem famílias. As observações e diários de campo nos permitem apontar alguns aspectos que demarcam histórias e sentidos singulares sobre modos de lidar com as mudanças ocorridas, atravessados pelos processos de desenvolvimento urbano de Aracaju, bem como pelo incremento do interesse turístico na região pelo Estado. Tais forças condicionantes produzem modos de viver ao tempo que deixam outros tantos perecerem e guardam em comum o fato de a vida das pessoas ter sido, em alguma medida, alterada em decorrência do crescimento do lugar onde vivem ou trabalham.

Tais aspectos podem ser agrupados em três grandes eixos de análise, que remetem às práticas sociais relacionadas aos impactos da degradação ambiental sobre a saúde das pessoas e seus estilos de vida.

\section{O processo saúde/doença relacionado às mudanças socioambientais}

Evidencia-se um modelo de desenvolvimento urbano devastador, afirmando a estreita relação entre os determinantes sociais da saúde e os processos de adoecimento. A degradação ambiental associada à falta de infraestrutura de escoamento de água e saneamento básico tem provocado efeitos desastrosos, dentre os quais se destacam as constantes inundações na área em períodos chuvosos.

Tal situação evidencia a complexidade do processo saúde-doença e a determinação de fatores históricos, ambientais, biológicos e sociais, que não podem ser considerados isoladamente, 
mas a partir da inter-relação entre eles, conforme apontado anteriormente por Minayo, Tambellini e Câmara. Longe da perspectiva de considerar que o desenvolvimento sustentável deve ter como foco central de suas ações a vida humana, o modelo de crescimento adotado segue sendo predatório, levando-nos a pensar num processo de degradação socioambiental da região, que inclui, simultaneamente, danos causados à população $e$ à natureza.

De modo que, poluição e uso indevido da água não potável, ausência de coleta regular de lixo e moradias insalubres são exemplos de exposição a riscos tradicionalmente reconhecidos como fatores prejudiciais à saúde que se verificam na região. A estes se juntam novas situações de vulnerabilidade provocadas pelo desemprego, aumento da criminalidade e violência, antes inexistentes na área. Crianças e idosos com problemas respiratórios, adultos com intenso sofrimento psíquico pela perda ou enfraquecimento de referências afetivas e culturais, adolescentes e jovens expostos à drogadição e exploração sexual, são casos emblemáticos de adoecimento físico e mental que chegam cotidianamente à rede de saúde.

\section{Atores sociais e usos do espaço urbano}

A partir do firmado na Conferência Rio 92, e ratificado na chamada Rio +20 , aponta-se a necessidade da conjugação de esforços de inúmeros atores sociais com vistas ao desenvolvimento sustentável. Estabelece-se que a necessidade de proteção do ambiente e dos recursos naturais, bem como da garantia de qualidade de vida das populações são ações sob a responsabilidade de todos. Por essa via, ressalta Cecília Minayo, além dos estados nacionais, também as empresas públicas e privadas, as organizações não governamentais e a sociedade civil devem desenvolver medidas que promovam mudanças.

O chamado Plano Diretor de Desenvolvimento Urbano Sustentável de Aracaju - PDDUS (criado em 2000 e em revisão na Câmara de Vereadores desde 2010), prevê a preservação e proteção de áreas ambientais. Nele, entretanto, a Zona de Expansão Urbana recebe várias denominações - Zona de Adensamento Restrito (ZAR), Área de Diretrizes Especiais de Interesse Ambiental (AIA) e Área de Interesse Urbanístico (AIU) -, o que sinaliza conflitos de interesses referentes à ocupação do território. Esta continua acontecendo de forma indiscriminada, com a conivência do Estado à implantação de projetos que respondem aos interesses da indústria do turismo e do mercado imobiliário, prioritariamente. Apenas medidas paliativas têm sido adotadas diante dos graves impactos ambientais que esses empreendimentos provocam ${ }^{24}$.

Por outro lado, também hábitos e costumes da própria população agravam o quadro de degradação ambiental e denotam o quanto se faz necessário um programa de educação em saúde na região. Dentre eles, podemos citar o acondicionamento indevido e as queimadas de lixo a céu aberto, a ingestão e uso de água imprópria para consumo, a criação de animais domésticos sem condições apropriadas de higiene.

Nesse quadro, se observa um paradoxo nas ações dos executores locais de políticas públicas de saúde e assistência: ou realizam um trabalho micropolítico por dentro da rede de saúde e/ou a partir das redes informais de sociabilidade, ou permanecem paralisados diante da complexidade do problema e da falta de recursos financeiros, humanos e sociais, necessários para levar a cabo iniciativas mais estruturais, no sentido de mitigar, prevenir e controlar situações ambientais causadoras de riscos e agravos à saúde.

Em geral, constata-se, como traço dominante, a implantação de ações de vigilância sanitária com pouca participação e sem controle social, que são, em última instância, normatizações que guardam uma enorme distância em relação àquilo que poderia ser um programa de educação em saúde. Finda que tais ações não produzem sentido na vida das pessoas, a ponto de desencadear mudanças significativas, acarretando o que se convencionou chamar de baixa adesão ao tratamento ou à reorientação de hábitos cotidianos.

\section{Práticas de enfrentamento ao problema da degradação socioambiental}

Destacam-se as ações dos ACS e dos profissionais das equipes da ESF no povoado em questão e em áreas vizinhas, que se dão em duas frentes: através de ações rotineiras de cuidado, reinventando aquilo que professam as políticas públicas oficiais, e reelaborando no espaço de trabalho a relação entre saúde e usuário, a partir daquilo que o morador lhe apresenta e através da escuta e busca de resolutividade dos problemas, inclusive daqueles que extrapolam a rede de saúde e exigem ações intersetoriais. Ressaltamos também a presença e persistência de práticas tradicionais de cura, exercidas por rezadeiras e pais-de-santo, que apontam a construção de itinerários terapêuticos singulares, paralelos ao uso da rede de saúde pública, voltados aos cuidados do corpo e ao alívio do sofrimento. Destaca-se 
também a importância das mulheres, que na sua potente capacidade de reinventar a vida em meio às adversidades do crescimento da região, dele também tiram proveito, alargando sua rede de sociabilidades e de antigos pescadores que agora passam a assumir outros ofícios.

Afirmando a perspectiva da ecosofia referida anteriormente, podemos dizer que, para além da questão ecológica propriamente dita, esses dados nos levaram a pensar no hibridismo das práticas locais, que juntam o antigo e o novo e produzem outros modos de vida e outras subjetividades, sugerindo a produção de re-existências cotidianas, como formas de enfrentamento ao empobrecimento, perda de vínculos sócio-comunitários, depressão, desemprego e outros fatores geradores de adoecimentos físicos e psíquicos.

\section{Considerações finais}

Os processos de adoecimento relacionados à degradação ambiental afirmam os determinantes sociais do processo saúde-doença e a necessidade de repensar tanto o modelo de desenvolvimento que vem sendo adotado, quanto práticas sociais e individuais de ressignificação dos modos de lidar com o meio ambiente. Porém, em meio ao modelo de desenvolvimento insustentável daquela região, algumas narrativas também apontaram para a invenção de formas de resistir ou se adequar a essas mudanças. São maneiras outras de fazer, as quais se constituem frente a uma tentativa de 'progresso' e urbanização de um povoado e a despeito dele. Maneiras de inventar a vida, de recriar formas e fazer valer algum sentido, ou não, para uma existência. Ações minúsculas, quase imperceptíveis, mas, por isso mesmo, muito importantes.

No que se refere às ações da rede de saúde, observamos que, para além das estatísticas oficiais que ressaltam ganhos no campo da epidemiologia, mas não revelam o sentido das práticas, a potência da ESF e em particular da ação bemsucedida desses trabalhadores, quando ocorre, não está linearmente atrelada a um modelo programático de intervenção sanitária - vacinação, controle dos casos de hipertensão e diabetes, acompanhamento de gestantes e nutrizes, assistência à saúde da criança etc. -, mas vinculada às práticas de cuidado no território, nas quais os ACS fortalecem vínculos já existentes com os moradores das comunidades onde vivem e trabalham ou tecem novas redes de sociabilidades.

Cuidar das pessoas seriamente, ouvir, implicar-se com suas histórias, comprometer-se politicamente com suas vidas, partilhar alegrias, buscar soluções coletivas aos inúmeros desafios com os quais se deparam, incluindo o desemprego, as agressões e violências, as precárias condições de moradia, os impactos da devastação ambiental sobre a vida e a saúde entre tantos outros, mobiliza os ACS e as equipes da ESF para dentro e para fora do campo da saúde, abrindo perspectivas de soluções que, muitas vezes, passam ao largo do Estado e encontram abrigo nas relações comunitárias.

Para além disso, porém, é evidente a necessidade da implantação de políticas ambientais que operem numa perspectiva de intersetorialidade, abrangendo ações de proteção e preservação ambiental em conjunto com as ações no campo da saúde e da assistência social, as quais possam promover a saúde e a qualidade de vida de populações ameaçadas por modelos de desenvolvimento predatório, como no caso deste estudo.

\section{Colaboradores}

LB Fonseca, MT Nobre e JJG Santos participaram de forma igual em todas as etapas da pesquisa e elaboração do presente artigo. 


\section{Referências}

1. França SLA, Resende VF. Conflitos Ambientais e Ocupação da Zona de Expansão Urbana de Aracaju: Distanciamento de uma Prática Sustentável. In: $V$ Encontro Nacional da Anppas; 4 a 7 de outubro de 2010; Florianópolis. [acessado 2011 set 2]. Disponível em: http:// www.anppas.org.br/encontro5/cd/artigos/GT3-470419-20100903191545.pdf

2. Santos M. O retorno do território In: Santos M, organizador Território: globalização e fragmentação. São Paulo: Annablume, Hucitec, Anpur; 2002. p. 15-20.

3. Brasil. Ministério da Saúde (MS). Manual de direito sanitário com enfoque na vigilância em saúde. Brasília: MS; 2006.

4. Minayo MCS. Saúde e ambiente. In: Campos GWS, Bonfim JRA, Minayo MCS, Akerman M, Drumond Júnior M, Carvalho YM. Tratado de Saúde Coletiva. São Paulo, Rio de Janeiro: Hucitec, Ed. Fiocruz; 2006. p. 81-109.

5. Brasil. Constituição da República Federativa do Brasil de 1988. Diário Oficial da União 1988; 5 out.

6. Brasil. Lei 8.080, de 19 de setembro de 1990. Dispõe sobre as condições para a promoção, proteção e recuperação da saúde, a organização e o funcionamento dos serviços correspondentes e dá outras providências. Diário Oficial da União 1990; 20 set.

7. Canguilhem G. O normal e o patológico. Rio de Janeiro: Forense Universitária; 2006.

8. Martins MC. As Narradoras de Itaoca: trabalho, infância e produção de saberes no cotidiano de mulheres pescadoras. In: Mendonça Filho MM, Nobre MT, Organizadores. Política e Afetividade: narrativas e trajetórias de pesquisa. Salvador, São Cristóvão: EDUFBA, EDUFS; 2009. p. 247-270.

9. Tambellini AT, Câmara VM. A temática saúde e ambiente no processo de desenvolvimento do campo da saúde coletiva: aspectos históricos, conceituais e metodológicos. Cien Saude Colet 1998; 3(2):47-59.

10. Castoriadis C, Cohen-Bendit D. Da ecologia à autonomia. São Paulo: Brasiliense; 1981.

11. Guattari F. As três ecologias. Campinas: Papirus; 1993.

12. Campos GWS. O SUS entre a tradição dos Sistemas Nacionais e o modo liberal-privado para organizar o cuidado à saúde. Cien Saude Colet 2007; 12(Supl.):18651874.
13. Lancetti A. Clínica Peripatética. São Paulo: Hucitec; 2008.

14. De Certeau M. A Invenção do Cotidiano. Petrópolis: Vozes; 2007.

15. Deleuze G, Parnet C. Diálogos. São Paulo: Editora Escuta; 1998.

16. Guattari F, Rolnik S. Micropolítica: cartografias do desejo. Petrópolis: Vozes; 1986.

17. Carvalho EM, Costa SL. As potências da narrativa. In: Lopes JKM, Carvalho EM, Matos KSAL, organizadores. Ética e as reverberações do fazer. Fortaleza: Edições UFC; 2011. p. 60-73.

18. Deleuze G. Conversações. São Paulo: Editora 34; 2008.

19. Benjamin W. Magia e técnica, arte e politica: ensaios sobre literatura e história da cultura. São Paulo: Brasiliense; 1994.

20. L'Abbate S. A análise institucional e saúde coletiva. Cien Saude Colet 2003; 8(1):265-274

21. Malinowski B. Argonautas do Pacífico Ocidental. São Paulo: Ed. Abril; 1978. (Coleção Os Pensadores)

22. Magnani JGC. Festa no Pedaço: cultura popular e lazer na cidade. $3^{\mathrm{a}}$ ed. São Paulo: Hucitec, UNESP; 2003.

23. Laplantine F. A Descrição Etnográfica. São Paulo: Terceira Margem; 2004.

24. Santos TL, Nobre MT. Discursos do estado e práticas de resistência da população no enfrentamento à degradação sócioambiental da área de expansão de Aracaju. In: Mendonça Filho M, Ferreri MA, organizadores. Instituições e cotidiano: formas e intensidades no enfrentamento do comum. São Cristóvão: Editora UFS; 2013. p. 181-207.

Artigo apresentado em 07/07/2014

Aprovado em 11/07/2014

Versão final apresentada em 12/07/2014 